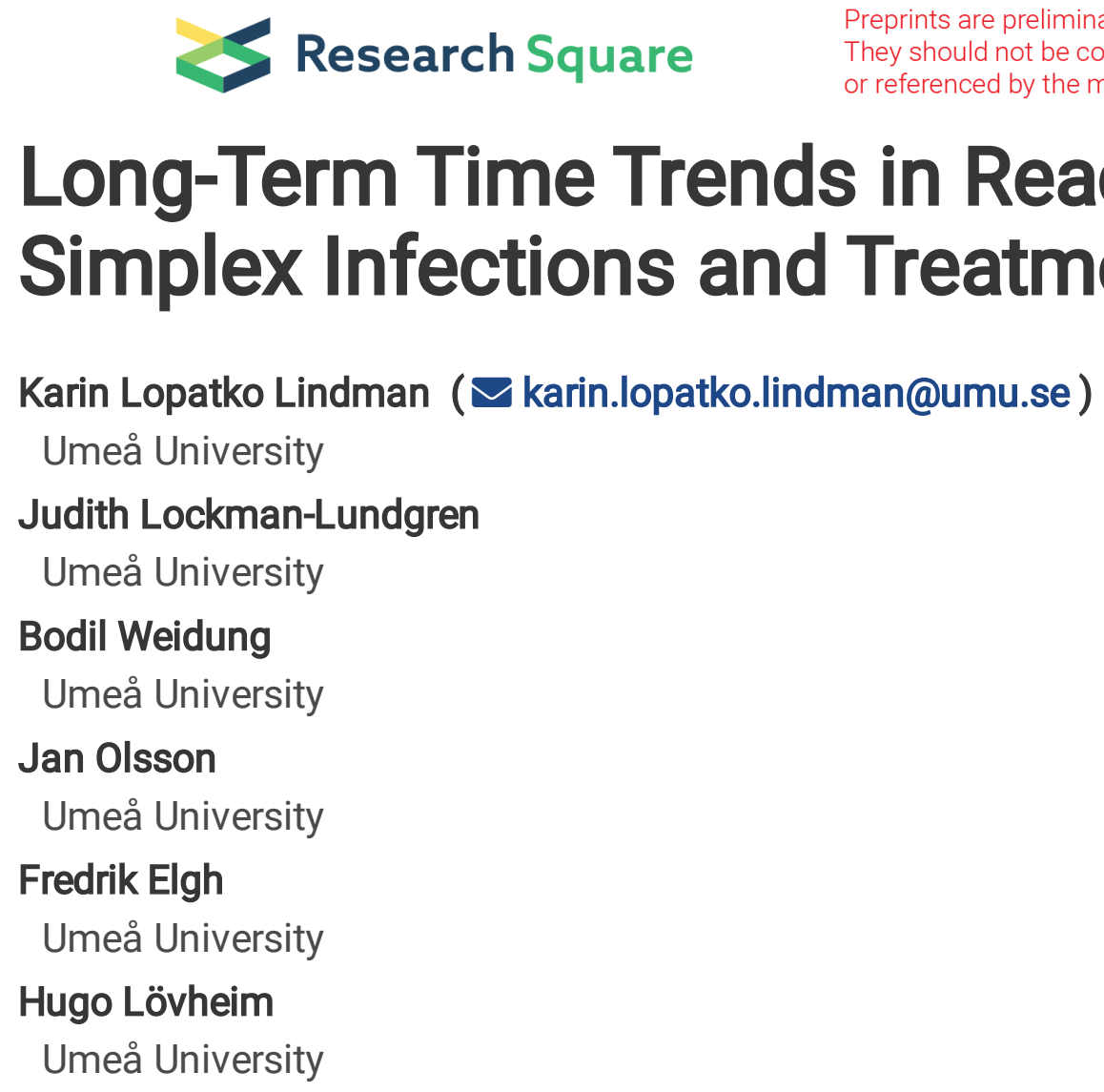

\title{
Long-Term Time Trends in Reactivated Herpes Simplex Infections and Treatment in Sweden.
}

\section{Research Article}

Keywords: Herpes Simplex, Antiviral agents, epidemiology, seroprevalence, Cohort study, Apolipoprotein E4, Ultraviolet radiation

Posted Date: August 5th, 2021

DOl: https://doi.org/10.21203/rs.3.rs-757417/v1

License: (c) (1) This work is licensed under a Creative Commons Attribution 4.0 International License. Read Full License 


\section{Abstract}

Background: Our aim was to describe the annual prevalence of herpes simplex virus (HSV) reactivation in relation to solar ultraviolet (UV) radiation and antiviral drug use in the Swedish adult population.

Methods: The study comprised 2,879 anti-HSV-1 immunoglobulin (Ig) G positive subjects from five different cohorts who had donated serum from 1988-2010. The sera were analyzed for anti-HSV IgM using enzyme-linked immunosorbent assay. Associations between the presence of anti-HSV IgM antibodies, the apolipoprotein E $\varepsilon 4$ allele and the serum sampling year were assessed by logistic regression. Seasonality of anti-HSV IgM was evaluated in a UV radiation model.

Data of antiviral drugs for the entire Swedish population were compiled from two different nationwide databases: the Swedish Prescribed Drug Register and the Swedish Association of the Pharmaceutical Industry.

Results: Cross-sectional and longitudinal analyses indicated that the prevalence of anti-HSV IgM antibodies declined between 1988 and 2010 (odds ratio [OR] $=0.912, P<.001$ ), while the total annual use of antiviral drugs in Sweden gradually increased from 1984 to 2017. Higher UV radiation was associated with higher prevalence of anti-HSV IgM antibodies $(\mathrm{OR}=1.071, P=.043)$.

Conclusion: The declining time trend of HSV reactivation coincides with a steady increase of antiviral drug use, indicating improved control of HSV reactivation in the Swedish adult population.

\section{Introduction}

Several studies have indicated a potential link between herpes simplex virus 1 (HSV-1) infection and the risk of Alzheimer's disease (AD) [1-3]. Also, recent findings suggest that antiviral treatment might offer some protection against the incidence of major neurocognitive disorders [4-6].

Herpesviruses are ubiquitous and an estimated $80 \%$ of the Swedish adult population is seropositive for HSV-1, 13\% for HSV-2 and 98\% for varicella zoster virus (VZV) [7]. Recurrent HSV and VZV infections are often treated with antiviral drugs, such as acyclovir and its prodrug valacyclovir that targets actively replicating herpesviruses, to reduce the duration of symptoms and viral shedding $[8,9]$.

Previous studies have reported a declining incidence of $A D$ and other neurocognitive disorders over the last decade [10-12]. Before, the age-adjusted incidence had been relatively stable during the last 50 years [13]. This observed trend break can be attributed partially to changes in the treatment and prevention of cardiovascular disease, as well as increasing educational attainment [11, 12]. Another potential contributing factor for the declining incidence of $A D$ could be the introduction of antiviral drugs against herpesviruses, at least in the subset of the population with HSV infection. This hypothesis is supported by the results from recent register-based studies, where use of antiviral drugs was associated with a lower risk of major neurocognitive disorders [4-6]. 
Previous reports of HSV-1 epidemiology have primarily focused on the seroprevalence of anti-HSV IgG and self-reported HSV reactivation, rather than time trends in reactivated infections [14-16]. In addition, only a few studies have specifically investigated the consumption rates of antiviral drugs in the general population [17]. Here, we set out to evaluate the time trends in the use of antivirals that target herpesviruses and reactivated HSV infections, as measured by the presence of anti-HSV IgM antibodies, in Sweden.

\section{Method}

\section{Antiviral drugs}

The annual prevalence of antiviral drugs between 1984 and 2017 were extracted from two nation-wide databases - the Swedish Prescribed Drug Register (SPDR) and the Swedish Association of the Pharmaceutical Industry (LIF). Anatomical Therapeutic Chemical (ATC) codes J05AB (J05A direct- acting antivirals: subgroup J05AB nucleosides and nucleotides excl. reverse transcriptase inhibitors) were used to identify drugs in SPDR and LIF. SPDR has had full coverage since 2006 and includes all prescription drugs dispensed by Swedish pharmacies [18]. In LIF, data were available on all doses delivered to Swedish pharmacies between 1984 and 2007.

The Defined Daily Dose (DDD) per year was calculated according to the guidelines of the World Health Organization Collaborating Centre for Drug Statistics Methodology. DDDs per 1000 inhabitants and year were calculated by dividing DDDs by the size of the Swedish population on 31 December each year, based on data obtained from Statistics Sweden and then multiplying the sum by 1000 . SPDR also includes the number of treated subjects per 1000 inhabitants and year stratified by age group and sex (Figure 1 B, showing data for 2017).

\section{The Betula study}

The Betula study is a prospective population-based cohort $[19,20]$. The study comprises five cohorts (samples [S] 1-5) enrolled at different time points at intervals of five years between 1988-1990 and 2008-2010 (time points [T] 1-5) Cross-sectional data from the first assessments of cohorts S1-5 and longitudinal data from cohorts S1 and S3 were available in the present study. S1 and S3 were monitored every five years until 2008-2010. The methods of selection and serological testing is described elsewhere [19-21]. In our study, only anti-HSV-1 IgG seropositive subjects were included.

\section{Serum analyses}

In short, a commercial enzyme-linked immunosorbent assay (ELISA) kit was used for the detection of anti-HSV1 IgG (HerpeSelect1, FOCUS Diagnostics) and an in-house ELISA was used for detection of antiHSV IgM as previously described [1].

The subjects' first serum sample was used to determine anti-HSV IgG status. If positive, this sample was further analyzed for specific anti-HSV-1 IgG, indicating carriage of HSV-1. Anti-HSV-1 IgG-positive 
samples were then analyzed for the presence of anti-HSV IgM, a marker of recent viral activity. The IgM ELISAs did not distinguish anti-HSV-1 from anti-HSV-2 IgM, and a positive sample may originate from reactivated HSV-1, reactivated HSV-2 or a primary infection with HSV-2.

Apolipoprotein $\mathrm{E}(A P O E)$ genotype was determined with a PCR-based assay as previously described [22]. For samples where DNA was unavailable, an APOEE4 specific ELISA (Cat \# K4699-100) (BioVision Inc., CA, USA) was employed for phenotypic assessment.

\section{UV data}

Data of daily (ultraviolet) UV radiation in Umeå, Sweden between 1991 and 1996 were publicly available and extracted from The Swedish Meteorological and Hydrological Institute (SMHI), registered according to previous publications $[23,24]$. The UV radiation was measured in minimum erythema dose (MED) per day where one MED is equal to the CIE-weighted irradiation of $210 \mathrm{Jm}^{-2}$. SMHI reports the mean daily MED value. The mean MED over five consecutive years was computed for each day of the year. Subjects were then assigned the mean MED matching their sampling day of the year. We estimated a non-linear regression curve since the plotted MED raw data varied greatly between summer and winter. $A$ multiplicative function of three sine waves provided a visually adequate fit to the data points.

\section{Statistics}

The use of antiviral drugs (total J05AB, as well as separately for the most common substances, acyclovir and valacyclovir) was calculated in the entire Swedish population every year from 1984 to 2017 to evaluate temporal trends. Herein, the term of "antiviral drugs in total" denotes all antiviral drugs with ATC codes J05AB. The distribution was also stratified by age and sex in 2017 to describe the treatment patterns regarding these factors.

A multivariable logistic regression model was fitted to anti-HSV IgM with sex, age, carriage of $A P O E \varepsilon 4$ (presence of one or two $\varepsilon 4$ alleles), sample year and UV radiation as covariates in the cross-sectional sample. We assured that the assumptions were met before performing the logistic regression analysis using the Box-Tidwell test and by plotting each independent variable against the prevalence of anti-HSV $\operatorname{lgM}$. A Pearson's or Phi correlation coefficient $\geq 0.5$ among two independent variables was regarded as a threshold value for multicollinearity.

The prevalence of anti-HSV IgM antibodies was examined both cross-sectionally and, for cohorts S1 and S3, also longitudinally. In the cross-sectional analyses, the subject's first available sample was used from time points T1-T4. In the longitudinal models, two cohorts (S1 and S3) were monitored from T1 (S1) and T2 (S3), respectively, until T5. Subgroup analyses were performed by sex and carriage of $A P O E \varepsilon 4$.

The prevalence of anti-HSV IgM for samples taken each day of the year was also plotted against solar UV radiation levels to visualize any seasonal variations in HSV infection. A time lag of 19 days between the exposure (MED function) and the outcome (simple sine function fitted to prevalence of IgM antibodies at 
each day of the year) was observed. The nineteen-day lag was subsequently used to account for the potential delay in IgM response after sun exposure when UV radiation ${ }_{(t=-19)}$, was added to the logistic regression model of anti-HSV IgM positivity. To compare the odds of anti-HSV IgM seropositive samples between summer and winter, the odds ratio (OR) of anti-HSV IgM positivity with UV radiation (t=-19) was raised to the power of the mean MED difference between summer months (June - August) and winter months (December - February).

Statistical analyses were performed using SPSS Statistics Version 25 (IBM Corporation, Armonk, NY). Diagrams were constructed in Microsoft Excel (Microsoft Corporation, Redmond, WA). A $P$ value $<.05$ was interpreted as significant.

\section{Results}

\section{Antiviral drugs}

Figure 1A shows the annual prevalence of antiviral drugs between 1984 and 2016. Since the introduction of acyclovir in 1984, there has been an almost linear increase in the overall use of antiviral drugs (Figure 1A). Acyclovir shows a pattern with two peaks, one in 1995 and the other in 2011. In contrast, the use of valacyclovir increased sharply after its introduction in 1995 and then reached a plateau. However, after 2010, the use of valacyclovir increased sharply again (Figure 1A).

Differences were observed in the use of antiviral drugs between males and females. In 2017, a higher proportion of females were using antiviral drugs compared to males, across all age groups (Figure 1B).

\section{Anti-HSV IgM}

In the present study, 2,879 subjects with anti-HSV-1 IgG antibodies were included from five different cohorts. 96 of these subjects (3.3\%) tested positive for anti-HSV IgM at the first individual serum sampling. With the exception of the summer months, the collection of blood samples was spread evenly throughout the year (30.7\% collected during winter, December - February, 30.5\% collected during spring, March - May, $6.5 \%$ collected during summer, June - August, and $32.3 \%$ collected during autumn, September - November). The prevalence of anti-HSV IgM at different sampling intervals and the baseline characteristics are presented in Table 1.

In the cross-sectional analyses, the highest proportion of anti-HSV IgM positive samples at baseline was observed at T1 (Table 1). For subsequent time points, the proportion of anti-HSV IgM positive samples were lower, and in particular at T4 (Table 1). Differences in anti-HSV IgM positive status between males and females are demonstrated in Figure 2A. Also, we found a higher prevalence of anti-HSV IgM among $A P O E \& 4$ carriers compared to non-carriers, at all different time points (Figure 2B).

Later sample year was associated with a lower prevalence of anti-HSV IgM antibodies (OR $=0.912$ per year, $P<.001$, Table 2), while UV radiation (t=-19) was associated with higher prevalence of anti-HSV IgM antibodies (OR $=1.071$ per MED, $P=.043$; Table 2). The mean MED difference between summer and winter months was 9.967 which is equal to $2093.07 \mathrm{Jm}^{-2}$. The odds for anti-HSV IgM positivity in summer 
were approximately two times higher than in winter ( $\mathrm{OR}=1.994$ per mean MED difference). Figure 3 illustrates the relationship between UV radiation (measured in MED) and the prevalence of anti-HSV IgM over one year, where the prevalence of anti-HSV IgM seems to follow the UV radiation with a delay of nineteen days.

\section{Discussion}

Here, we investigated two possibly related time trends: the total use of antiviral drugs targeting herpesviruses since their introduction in 1984 until 2017 and the prevalence of reactivated HSV infection in a Swedish cohort sampled between 1988 and 2010. The overall use of antiviral drugs in Sweden has gradually increased while the prevalence of reactivated HSV infection in the studied cohort show a declining trend.

Our results of an overall higher antiviral drug use are in accordance with previous reports, indicating increasing antiviral treatment rates against herpes zoster in Canada and higher antiviral use among pregnant women in the United States $[17,25]$. A reduction of acyclovir prescriptions after an initial peak in 1995, which was observed in the present study, could be explained by the introduction of valacyclovir in 1995. A second peak in acyclovir prescriptions occurred in parallel with the expiry of the patent for acyclovir and subsequent price cuts in 1997. Finally, a subsequent decline in acyclovir prescriptions occurred when the patent for valacyclovir expired in 2009 and the price of valacyclovir decreased. The reason for the two partially overlapping data series in Figure 1 is because we extracted drug data from two different sources, in which LIF has information about doses delivered to pharmacies (1984 to 2007) and SPDR includes all dispensed drugs (2006 to 2016). However, data on the percentage of dispensed doses among the doses delivered to pharmacies were not available in LIF. This explains the slightly higher prevalence of antiviral drugs in the overlapping years of 2006 and 2007 in Figure 1A.

The decline in HSV reactivations among individuals with HSV-1 in our material was demonstrated both between and within the sub-cohorts. These findings may imply an improvement in the immunological control of herpes infections. It seems plausible that the increasing use of antiviral drugs in Sweden may have contributed to this decline; early treatment with antiviral drugs at the first sign of symptoms could possibly prevent the production of IgM antibodies. Notably, previous clinical trials have not detected any effect on recurrence rates with episodic acyclovir after discontinuation [8, 9], indicating that the effect of antiviral drugs is limited to the current reactivation.

Our results could be interpreted in the light of previous findings indicating that HSV-1 reactivation, measured as the presence of anti-HSV IgM antibodies, is associated with increased risk of subsequent $A D[1,3]$, while antiviral treatment might reduce this risk [4-6]. Interestingly, the incidence of major neurocognitive disorders in Sweden appears to have declined from 2010 and onwards [10]. However, whether the growing use of antiviral drugs in Sweden could have impacted the incidence of AD cannot be established from the observation of these parallel trends. 
At T1 and T2, women had a higher proportion of anti-HSV IgM positive samples, but at subsequent time points, this proportion had changed. Women also received antiviral drugs more often and this higher use of antivirals could perhaps explain the more pronounced reduction in the prevalence of anti-HSV IgM antibodies among women. Although not significant, we also observed a tendency for APOE 44 carriers to have an increased risk of anti-HSV IgM seropositivity (Table 2 and Figure 2B), in line with other studies indicating a link between HSV-1 and the APOE 84 allele [21, 26-28].

The distribution of anti-HSV IgM seropositive samples showed a seasonal variation and seemed to relate with the changes in UV radiation. Exposure to UV radiation is a known trigger of HSV reactivation [29] and higher UV index was previously found to associate with recurrence of ocular HSV under certain conditions [30]. Previous studies of UV radiation and HSV reactivations have mainly examined high risk groups with prior history of recurrent infections or have had small population samples. Our cohort consisting of a large, unselected sample could therefore provide additional support to the relationship between UV exposure and HSV reactivations in the general population. However, other causes of HSV reactivation during summer have to be considered.

The strengths of our investigation are that we used nationwide registers that reflect drug prescriptions in the entire Swedish population. Conversely, the primary strengths of the Betula cohort study relate to the large population-based sample and long follow-up period. A significant limitation is the small number of individuals positive for anti-HSV IgM antibodies and that individual drug data were not available for the cohort study population. Our results are also descriptive of the trends in two diverse measures in different samples and therefore do not prove any causal link, which must be taken into account when interpreting the results.

\section{Conclusion}

Antiviral drugs have become increasingly common since acyclovir was introduced in 1984. Since 2000, there has been a marked decline in the prevalence of recent HSV infection among HSV-1 seropositive individuals, indicating improved control of herpesvirus infections in the Swedish adult population. We also noted a seasonal variation where the distribution of anti-HSV IgM seropositive samples seemed to relate with changes in UV radiation.

\section{Abbreviations}

HSV - herpes simplex virus

AD - Alzheimer's disease

VZV - varicella zoster virus

Ig - Immunoglobulin 
SPDR - the Swedish Prescribed Drug Register

LIF - the Swedish Association of the Pharmaceutical Industry

ATC - Anatomical Therapeutic Chemical

DDD - The Defined Daily Dose

ELISA - enzyme-linked immunosorbent assay

APOE- Apolipoprotein E

UV - ultraviolet

SMHI - The Swedish Meteorological and Hydrological Institute

MED - minimum erythema dose

$\mathrm{OR}$ - odds ratio

\section{Declarations}

\section{Ethical approval and consent to participate}

The study was approved by the Regional Ethical Review Board in Umeå, Sweden (2010-229-31 M). The participants previously gave their consent to publications and research of stored serum samples.

Consent for publication

All authors have approved the final version of the manuscript.

Availability of data and materials

The Betula dataset used in the current study is available from the corresponding author on reasonable request. The dataset of drug prescriptions was extracted from the open database of the National Board of Health and Welfare and the Swedish Association of the Pharmaceutical Industry.

Competing interests

Nothing to declare.

Financial support

This work was financially supported by Västerbotten County Council, the Kempe Foundations, the Swedish Medical Association, the Swedish Dementia Association, the Trolle-Wachtmeister Foundation, 
the Northland Dementia Fund, the Swedish Alzheimer Fund, the Stohne Foundation and the Umeå University Foundation for Medical Research.

\section{Author contributions}

All authors contributed to and approved the final version. FE and HL designed and initialized the study. FE and $\mathrm{JO}$ were responsible for serological testing. $\mathrm{KLL}$, JLL, and $\mathrm{HL}$ performed the statistical analyses. $\mathrm{KLL}$, JLL, BW and $\mathrm{HL}$ were major contributors to interpreting the results and were primarily responsible for writing the manuscript.

\section{Acknowledgments}

The authors wish to express their gratitude to Emma Honkala for laboratory assistance.

\section{References}

1. Lovheim H, Gilthorpe J, Adolfsson R, Nilsson LG, Elgh F: Reactivated herpes simplex infection increases the risk of Alzheimer's disease. Alzheimer's \& dementia : the journal of the Alzheimer's Association 2015, 11(6):593-599.

2. Lovheim H, Gilthorpe J, Johansson A, Eriksson S, Hallmans G, Elgh F: Herpes simplex infection and the risk of Alzheimer's disease: A nested case-control study. Alzheimer's \& dementia : the journal of the Alzheimer's Association 2015, 11(6):587-592.

3. Letenneur L, Peres K, Fleury H, Garrigue I, Barberger-Gateau P, Helmer C, Orgogozo JM, Gauthier S, Dartigues JF: Seropositivity to herpes simplex virus antibodies and risk of Alzheimer's disease: a population-based cohort study. PloS one 2008, 3(11):e3637.

4. Tzeng NS, Chung $\mathrm{CH}$, Lin FH, Chiang CP, Yeh CB, Huang SY, Lu RB, Chang HA, Kao YC, Yeh HW et al: Anti-herpetic Medications and Reduced Risk of Dementia in Patients with Herpes Simplex Virus Infections-a Nationwide, Population-Based Cohort Study in Taiwan. Neurotherapeutics 2018, 15(2):417429.

5. Bae S, Yun SC, Kim MC, Yoon W, Lim JS, Lee SO, Choi SH, Kim YS, Woo JH, Kim SY et al: Association of herpes zoster with dementia and effect of antiviral therapy on dementia: a population-based cohort study. Eur Arch Psychiatry Clin Neurosci 2020.

6. Lopatko Lindman K, Hemmingsson ES, Weidung B, Brännström J, Josefsson M, Olsson J, Elgh F, Nordström P, Lövheim H: Herpesvirus infections, antiviral treatment, and the risk of dementia-a registrybased cohort study in Sweden. Alzheimers Dement (N Y) 2021, 7(1):e12119.

7. Olsson J, Kok E, Adolfsson R, Lovheim H, Elgh F: Herpes virus seroepidemiology in the adult Swedish population. Immunity \& ageing : / \& A 2017, 14:10. 
8. Nilsen AE, Aasen T, Halsos AM, Kinge BR, Tjotta EA, Wikstrom K, Fiddian AP: Efficacy of oral acyclovir in the treatment of initial and recurrent genital herpes. Lancet (London, England) 1982, 2(8298):571-573.

9. Reichman RC, Badger GJ, Mertz GJ, Corey L, Richman DD, Connor JD, Redfield D, Savoia MC, Oxman $\mathrm{MN}$, Bryson $\mathrm{Y}$ et al: Treatment of recurrent genital herpes simplex infections with oral acyclovir. A controlled trial. Jama 1984, 251(16):2103-2107.

10. Seblova D, Quiroga ML, Fors S, Johnell K, Lovden M, de Leon AP, Svensson AC, Wicks S, Lager A: Thirty-year trends in dementia: a nationwide population study of Swedish inpatient records. Clin Epidemio/ 2018, 10:1679-1693.

11. Derby CA, Katz MJ, Lipton RB, Hall CB: Trends in Dementia Incidence in a Birth Cohort Analysis of the Einstein Aging Study. JAMA Neurol 2017, 74(11):1345-1351.

12. Wu YT, Fratiglioni L, Matthews FE, Lobo A, Breteler MM, Skoog I, Brayne C: Dementia in western Europe: epidemiological evidence and implications for policy making. The Lancet Neurology 2016, 15(1):116-124.

13. Rocca WA, Petersen RC, Knopman DS, Hebert LE, Evans DA, Hall KS, Gao S, Unverzagt FW, Langa KM, Larson EB et al: Trends in the incidence and prevalence of Alzheimer's disease, dementia, and cognitive impairment in the United States. Alzheimer's \& dementia : the journal of the Alzheimer's Association 2011, 7(1):80-93.

14. Forbes H, Warne B, Doelken L, Brenner N, Waterboer T, Luben R, Wareham NJ, Warren-Gash C, GkraniaKlotsas E: Risk factors for herpes simplex virus type-1 infection and reactivation: Cross-sectional studies among EPIC-Norfolk participants. PloS one 2019, 14(5):e0215553.

15. Cohen JA, Sellers A, Sunil TS, Matthews PE, Okulicz JF: Herpes simplex virus seroprevalence and seroconversion among active duty US air force members with HIV infection. J Clin Virol 2016, 74:4-7.

16. Delaney S, Gardella C, Saracino M, Magaret A, Wald A: Seroprevalence of herpes simplex virus type 1 and 2 among pregnant women, 1989-2010. Jama 2014, 312(7):746-748.

17. Friesen KJ, Alessi-Severini S, Chateau D, Falk J, Bugden S: The changing landscape of antiviral treatment of herpes zoster: a 17-year population-based cohort study. Clinicoecon Outcomes Res 2016, 8:207-214.

18. Wettermark B, Hammar N, Fored CM, Leimanis A, Otterblad Olausson P, Bergman U, Persson I, Sundstrom A, Westerholm B, Rosen M: The new Swedish Prescribed Drug Register-opportunities for pharmacoepidemiological research and experience from the first six months. Pharmacoepidemiol Drug Saf 2007, 16(7):726-735.

19. Josefsson M, de Luna X, Pudas S, Nilsson LG, Nyberg L: Genetic and lifestyle predictors of 15-year longitudinal change in episodic memory. J Am Geriatr Soc 2012, 60(12):2308-2312. 
20. Nyberg L, Boraxbekk CJ, Sörman DE, Hansson P, Herlitz A, Kauppi K, Ljungberg JK, Lövheim H, Lundquist A, Adolfsson AN et al: Biological and environmental predictors of heterogeneity in neurocognitive ageing: Evidence from Betula and other longitudinal studies. Ageing Res Rev 2020, 64:101184.

21. Lovheim H, Norman T, Weidung B, Olsson J, Josefsson M, Adolfsson R, Nyberg L, Elgh F: Herpes Simplex Virus, APOEvarepsilon4, and Cognitive Decline in Old Age: Results from the Betula Cohort Study. $J$ Alzheimers Dis 2019, 67(1):211-220.

22. Sundstrom A, Marklund P, Nilsson LG, Cruts M, Adolfsson R, Van Broeckhoven C, Nyberg L: APOE influences on neuropsychological function after mild head injury: within-person comparisons. Neurology 2004, 62(11):1963-1966.

23. Josefsson W: Five years of solar UV-radiation monitoring in Sweden. https://www.smhi.se/publikationer/uv-radiation-measured-in-norrkoping-1983-2003-1.1906 1996. Accessed 11 January 2021

24. Josefsson W: Solar UV-radiation monitoring 1996.https://www.smhi.se/publikationer/solar-uvradiation-monitoring-1996-1.2821 1996. Accessed 11 January 2021.

25. Avalos LA, Chen H, Yang C, Andrade SE, Cooper WO, Cheetham CT, Davis RL, Dublin S, Hammad TA, Kaplan $S$ et al: The prevalence and trends of antiviral medication use during pregnancy in the US: a population-based study of 664,297 deliveries in 2001-2007. Matern Child Health J 2014, 18(1):64-72.

26. Itzhaki RF, Lin WR, Shang D, Wilcock GK, Faragher B, Jamieson GA: Herpes simplex virus type 1 in brain and risk of Alzheimer's disease. Lancet (London, England) 1997, 349(9047):241-244.

27. Lopatko Lindman K, Weidung B, Olsson J, Josefsson M, Kok E, Johansson A, Eriksson S, Hallmans G, Elgh F, Lövheim H: A genetic signature including apolipoprotein E\&4 potentiates the risk of herpes simplex-associated Alzheimer's disease. Alzheimers Dement (N Y) 2019, 5:697-704.

28. Linard M, Letenneur L, Garrigue I, Doize A, Dartigues JF, Helmer C: Interaction between APOE4 and herpes simplex virus type 1 in Alzheimer's disease. Alzheimer's \& dementia : the journal of the Alzheimer's Association 2020, 16(1):200-208.

29. Rooney JF, Bryson Y, Mannix ML, Dillon M, Wohlenberg CR, Banks S, Wallington CJ, Notkins AL, Straus SE: Prevention of ultraviolet-light-induced herpes labialis by sunscreen. Lancet (London, England) 1991, 338(8780):1419-1422.

30. Ludema C, Cole SR, Poole C, Smith JS, Schoenbach VJ, Wilhelmus KR: Association between unprotected ultraviolet radiation exposure and recurrence of ocular herpes simplex virus. American journal of epidemiology 2014, 179(2):208-215. 


\section{Tables}

Table 1. Baseline characteristics in cohorts S1 to S5

\begin{tabular}{|c|c|c|c|c|c|}
\hline Cohorts & S1 & S2 & S3 & S4 & S5 \\
\hline n & 764 & 774 & 638 & 278 & 425 \\
\hline Age range, $y^{*}$ & $35-91$ & $35-81$ & $59-90$ & $60-91$ & $35-95$ \\
\hline Age, $y$, mean $\pm S D$ a & $61.7 \pm 14.1$ & $59.9 \pm 14.0$ & $69.8 \pm 9.0$ & $74.1 \pm 9.2$ & $62.9 \pm 16.0$ \\
\hline Female, n (\%) & $411(53.8)$ & $436(56.3)$ & $376(58.9)$ & $139(50.0)$ & $218(51.3)$ \\
\hline$A P O E \varepsilon 4$ carriers, $\mathrm{n}(\%)$ & $227(29.7 \%)$ & $226(29.2 \%)$ & $183(28.7 \%)$ & $72(25.9 \%)$ & $89(20.9 \%)$ \\
\hline \multicolumn{6}{|l|}{ Sampling year, $\mathrm{n}$} \\
\hline \multicolumn{6}{|l|}{ Anti-HSV IgM positive samples/ $n$ (\%). } \\
\hline T1: 1988-1990 & $30 / 590(5.1)$ & & & & \\
\hline T2: 1993-1995 & $12 / 454(2.6)$ & $30 / 774(3.9)$ & $17 / 492(3.5)$ & & \\
\hline T3: $1998-2000$ & $27 / 381(7.1)$ & & 29/471 (6.2) & $9 / 278(3.2)$ & \\
\hline T4: 2003-2005 & $3 / 339(0.9)$ & & $1 / 386(0.3)$ & & $3 / 425(0.7)$ \\
\hline T5: 2008-2010 & $1 / 246(0.4)$ & & $1 / 222(0.5)$ & & \\
\hline First sample, $n$ & $35 / 764(4.6)$ & $30 / 774(3.9)$ & $19 / 638(3.0)$ & $9 / 278(3.2)$ & $3 / 425(0.7)$ \\
\hline anti-HSV lgM positive samples/ n (\% & & & & & \\
\hline
\end{tabular}

Abbreviations: $\mathrm{n}$, number; $\mathrm{y}$, years; $\mathrm{SD}$, standard deviation; $A P O E \varepsilon 4$, apolipoprotein $\mathrm{E}$ allele 4; Immunoglobulin M, IgM

a On the date of the first included serum sample.

Table 2. Logistic regression of anti-HSV IgM with sex, age, $A P O E \varepsilon 4$, sampling year and UV radiation. 


\begin{tabular}{|c|c|c|c|}
\hline & Odds ratio & $95 \%$ Confidence interval & $P$-value \\
\hline Sex (reference: female) & 0.801 & $0.528-1.218$ & .300 \\
\hline Age & 1.009 & $0.993-1.024$ & .271 \\
\hline Carriage of $A P O E \varepsilon 4$ & 1.466 & $0.956-2.247$ & .079 \\
\hline Sampling year & 0.912 & $0.868-0.960$ & $<.001$ \\
\hline UV radiation(t=-19). & 1.071 & $1.002-1.145$ & .043 \\
\hline
\end{tabular}

\section{Figures}
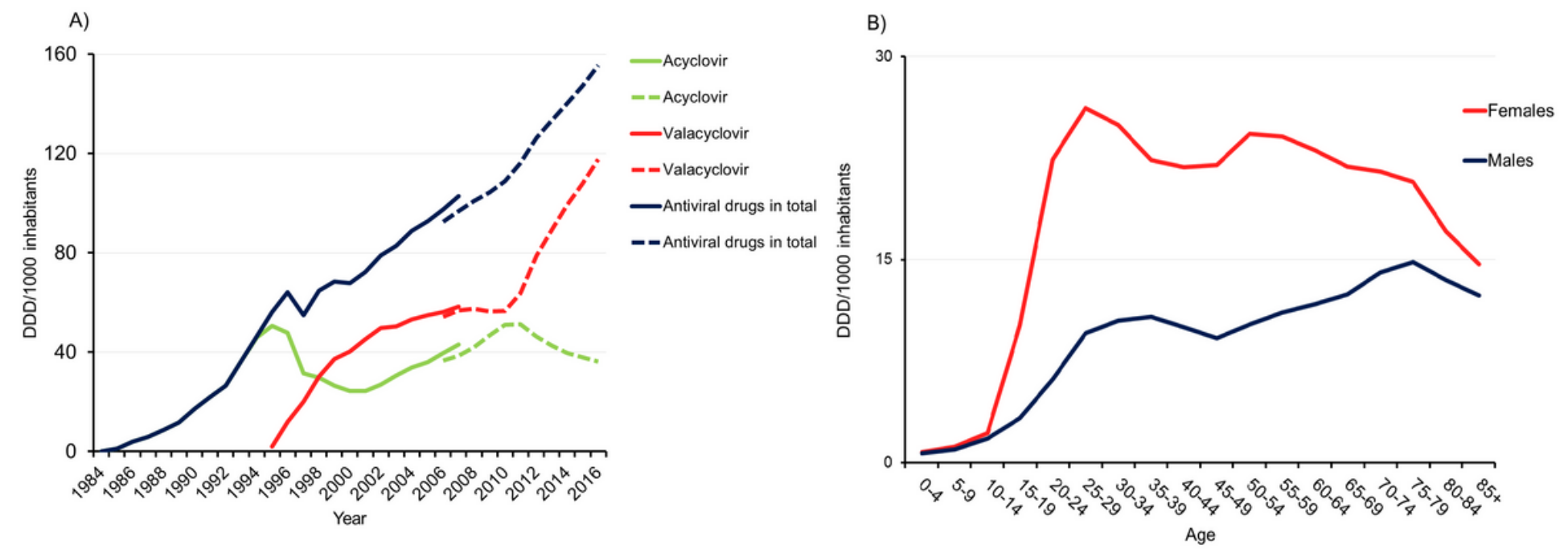

Figure 1

The use of antiviral drugs in Sweden. The continuous line in the diagram represents drug data collected from the LIF (1984 to 2007) and the dotted line represents SPDR data (2006 to 2017). A) The use of antiviral drugs in DDD/1000 inhabitants per year from 1984-2016 in Sweden, collected from two databases, the Swedish Association of the Pharmaceutical Industry (1984-2007) and the Swedish Prescribed Drug Register (2006-2016). B) The number of subjects with antiviral drugs/1000 inhabitants stratified by sex and age group in 2017 in Sweden. 

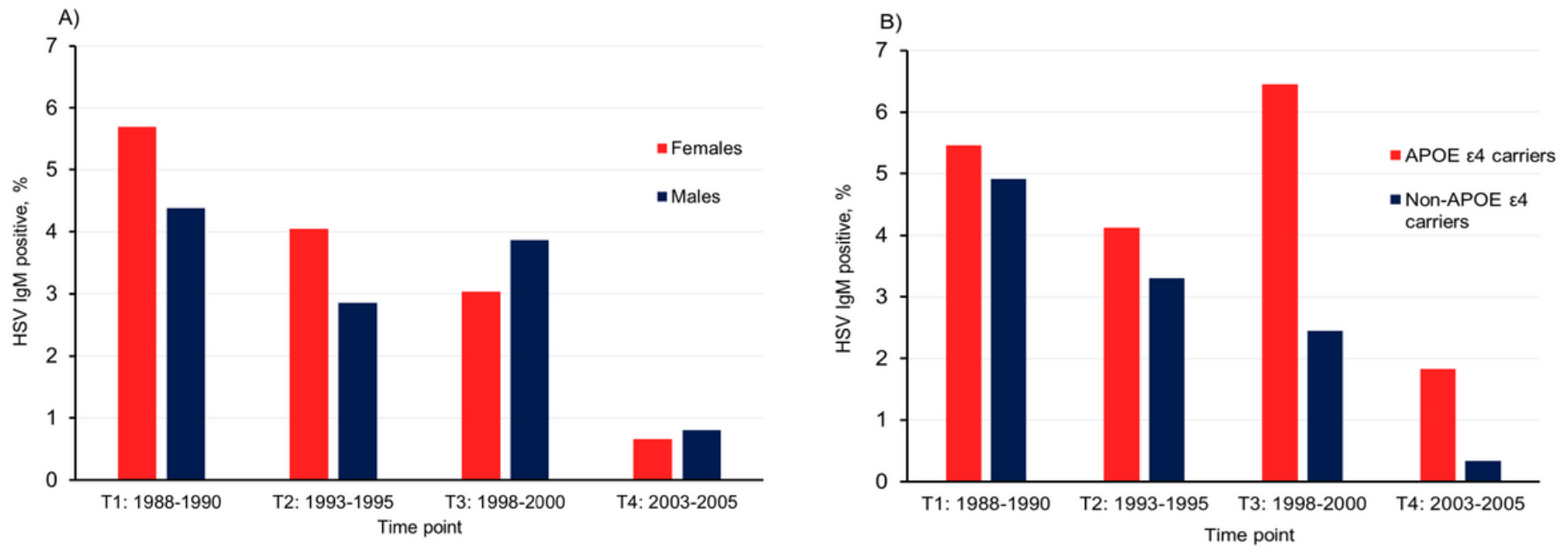

Figure 2

Anti-HSV IgM positivity in the Betula cohort. A) Cross-sectional comparisons of the prevalence of antiHSV IgM at first sampling between males and females at different time points. B) Cross-sectional comparisons of the prevalence of anti-HSV IgM at first sampling between APOE $\varepsilon 4$ carriers and nonAPOE $\varepsilon 4$ carriers. 


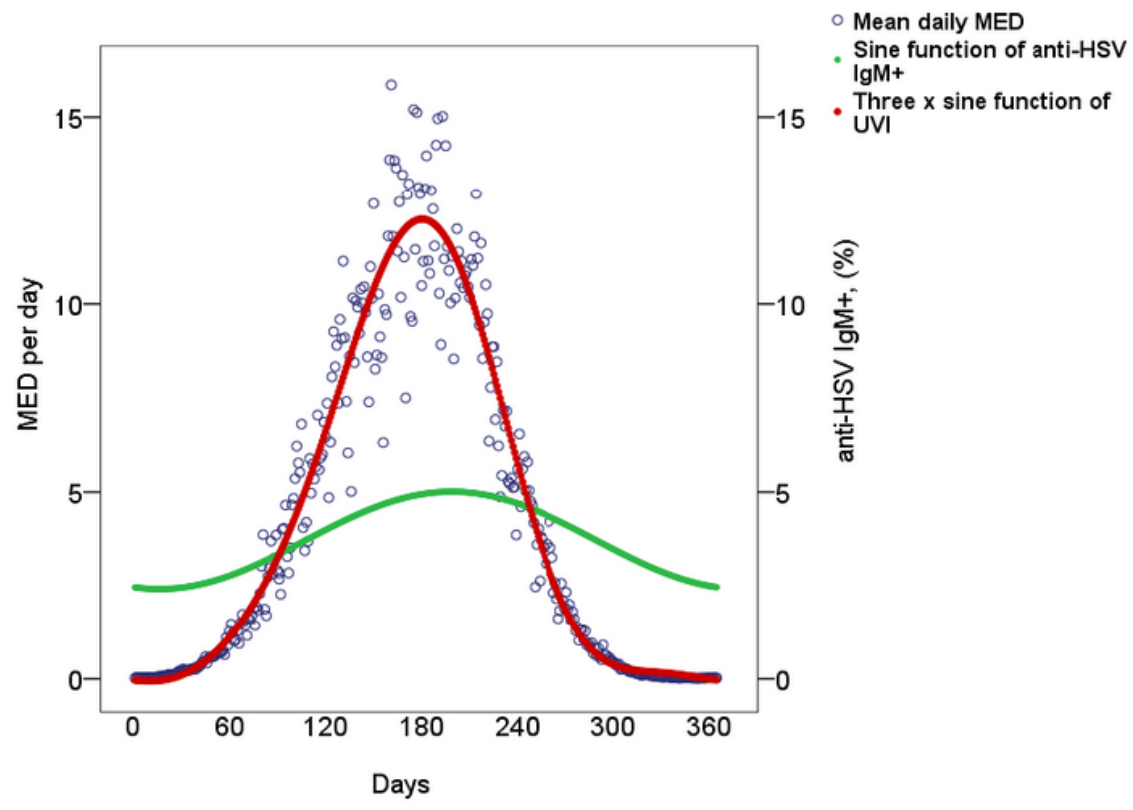

\section{Figure 3}

Anti-HSV IgM positivity in the Betula cohort. Cross-sectional comparisons of the prevalence of anti-HSV IgM at first sampling, sampling day and UV radiation(t=-19) in Umeå, Sweden. 